\title{
Does ACTH mediate the punishment-intensification effect of prolonged, fixed-duration treatment shocks?
}

\author{
D. CHRIS ANDERSON \\ University of Notre Dame, Notre Dame, Indiana
}

\begin{abstract}
Dexamethasone (DEX) was used to suppress adrenocorticotrophic hormone (ACTH) liberation during shock treatment (ST), punishment testing, or both, for four groups of rats (the same injection pattern was also given to four non-ST groups). ST facilitated punishment learning equally for groups given either saline or DEX for both treatment and testing, whereas ST groups that were switched (from treatment DEX to test saline or from treatment saline to test DEX) performed more like non-ST controls. DEX also produced marked weight losses, suppressed pretest baseline responding and, when given only during testing, modestly offset punishment learning. The theory that ACTH is a source of memory retrieval was consistent with this finding that punishment-facilitation effects of ST are (partly) mediated by cues associated with elevated pituitary-adrenal output. However, the similar mediational effect of DEX cues was consistent with a more general internal-cue conditioning interpretation of ST effects.
\end{abstract}

There is considerable evidence showing that adrenocorticotrophic hormone (ACTH) can influence the acquisition, retention, and extinction of aversively motivated behaviors (see reviews by McGaugh, 1983, and Riccio \& Concannon, 1981). For example, several authors have shown that ACTH (both endogenous and exogenous) seems to be necessary for the acquisition of response suppression to response-contingent shocks, that is, punishment learning (Anderson, Winn, \& Tam, 1968; De Wied, 1974; Levine \& Jones, 1965; Levine \& Levin, 1970). Others have identified ACTH as a source of memory retrieval for behaviors impaired or hindered by various treatments-for example, instances in which ACTH promoted recovery from a performance decrement resulting from exposure to an amnestic agent (Mactutus, Smith, \& Riccio, 1980) or from an alteration in environmental cues (Concannon, Riccio, Maloney, \& McKelvey, 1980). Similarly, Rigter, Elbertse, and van Riezen (1975), in injecting an ACTH peptide fragment $\left(\mathrm{ACTH}_{4-10}\right)$ that did not elevate glucocorticoid levels, found alleviation of the retrograde amnesia caused by electroconvulsive shock. Finally, Richardson, Riccio, and Devine (1984) reported that partially extinguished avoidance and punished behaviors showed recovery in response to ACTH injections. Moreover, Ahlers and Richardson (1985) found that this influence of ACTH on recovery of an extinguished avoid-

This paper was presented in part in November 1992 at the 33rd Annual Meeting of the Psychonomic Society, St. Louis. Special thanks is given to J. Rollins, J. Madden, IV, J. Moskal, M. Noonan, R. Conner, and $R$. Fitzgerald for their assistance in the conduct and/or evaluation of this study. Correspondence should be addressed to D. C. Anderson, Department of Psychology, 112 Haggar Hall, University of Notre Dame, Notre Dame, IN 46556. ance response was not due to a "disinhibitory" effect that may occur upon the introduction of novel stimuli.

A possible account (hereafter termed the facilitated memory retrieval [FMR] theory) of certain of these effects rests on the view that the aversive stimulus involved in response training provokes the liberation of ACTH. A memorial association is believed to develop between the contiguous presence of these ACTH cues and aspects of the training regimen. Pretest introduction of ACTH (following extinction or other performance-decrementing treatments) thus occasions the reinstatement of the training memory that, in turn, putatively facilitates improved performance of the decremented behavior (see McGaugh, Gold, Van Buskirk, \& Haycock, 1975).

This theory also may apply to phenomena wherein treatments have been shown to intensify (rather than decrement) response learning. One such treatment involves exposure of subjects to a series of relatively prolonged, painful, unsignaled, and fixed-duration electric shocks (ST). Madden, Rollins, Anderson, Conner, and Levine (1971) showed that this treatment not only facilitates punishment learning (see also Anderson, Cole, \& McVaugh, 1968, and Walters \& Rogers, 1963) but also elevates circulating plasma corticosterone indicative of ACTH level (see also Maier, Ryan, Barksdale, \& Kalin, 1986), both immediately following ST and the subsequent test shock.

At least one response class consistently has been shown to develop during ST - namely, attenuated movement or freezing (Anderson, Crowell, Cunningham, \& Lupo, 1979; Balleine \& Job, 1991; Crowell \& Anderson, 1981; Mineka, Cook, \& Miller, 1984). The presence of high levels of endogenous ACTH during ST (i.e., training) ac- 
cordingly may result in a memorial linkage with this response tendency. Reoccurrence of ACTH during punishment testing thus could facilitate retrieval of this training memory that, in turn, would occasion freezing in the test setting. Since freezing is compatible with the response suppression defining a punishment contingency, this could account for the punishment-facilitation effect of ST. It follows that if ACTH cues serve an important role in mediating this effect as outlined, then their elimination during ST should offset the development of training memory linkages and, consequently, should reduce the intensifying effect of this treatment on punishment testing.

Dexamethasone (DEX) was used to manipulate the presence and absence of ACTH (and related pituitary-adrenal [PA] outputs) in the present study. There is considerable evidence for the suppressive effect of DEX on ACTH liberation (Ahlers \& Richardson, 1985; P. A. Beatty, W. W. Beatty, Bowman, \& Gilchrist, 1970; Heinsbroek, Van Oyen, Van De Poll, \& Boer, 1983; Hennessy, Smotherman, \& Levine, 1980; Levine \& Levin, 1970; Seggie \& Brown, 1973; but see Britton, Lec, Bana, Risch, \& Koob, 1986, and Lamberts, Bons, \& Zuiderwijk, 1986). To fully evaluate the possible associative contributions of ACTH, the presence and absence of DEX (and hence of ACTH) was factorially crossed with all levels of the treatment and test conditions.

\section{METHOD}

\section{Subjects}

Seventy-two naive albino male Sprague-Dawley rats, $90-110$ days old and purchased from Sprague-Dawley, Inc., Madison, WI, were used. All were caged singly and provided free access to food and water during acclimation to the lab (this included daily handling and weighing). Although the experiment was conducted prior to the formation of the local Animal Research Screening Committee (ARSC), the major features of this study (including shock parameters, animal-care practices, and so on) conformed to those subsequently approved by this group. Lighting in the room that housed the subjects was continuous $(24 \mathrm{~h})$, and the intensity level was below that subsequently established by the ARSC as detrimental to the health and/or vision of the subjects. Research was conducted between 0800 and $1200 \mathrm{~h}$.

\section{Apparatus}

Different chambers were used for ST and testing. The ST chamber $(25.3 \times 17.7 \times 17.7 \mathrm{~cm}$, height, width, and length, respectively) was composed of stainless steel walls and a floor made of $0.63-\mathrm{cm}-$ diam grids placed $1.9 \mathrm{~cm}$ apart from the centers, and was enclosed in a larger wooden box that was situated within a darkened, soundattenuated, and ventilated refrigerator shell. A ventilation fan 1ocated outside the shell supplied a constant, 65 -db masking noise. The ST was supplied by a tube-regulated, constant-current (dc) device (Campbell \& Teghtsoonian, 1958) set at $0.8 \mathrm{~mA}$, and the shocks were delivered through a grid scrambler (Davis, Model 255). All stimulus parameters were controlled by automated switches and a computer located in a distant room.

The test chamber was a modified Gerbrands operant conditioning box (Model 4C) consisting of a grid floor, Plexiglas sides and lid, and aluminum end walls. A stainless steel rat bar was located in the center of one end wall and was (approximately) shoulder height with most of the animals. A food cup was present in a recessed area below and to the left of the bar. Automated activation of a rotary feeder permitted food delivery upon the occurrence of a barpress. This chamber also was fitted into a sound- and light-controlled refrigerator shell illuminated from above by a 7.5-W lamp. A ventilation fan provided a constant $65-\mathrm{db}$ masking background noise. A scrambled shock source could be activated via a computer connected through a relay interface to deliver a $0.5-\mathrm{sec}, 0.8-\mathrm{mA}$, constant-current (dc) shock.

\section{Design}

Following barpress training for food, the subjects from two large groups were placed individually into the ST chamber on each of 5 consecutive days (Days 18-22). Prior to each placement, the rats from one of these groups were given subcutaneous injections of DEX; the rats in the other group were given comparable injections of saline. Half of each of these groups were given ST, and the others were not shocked (NST). Half of the rats from each of these treatment conditions again were injected with DEX; the rest were injected with saline prior to each of three punishment test sessions (Days 41-43).

These manipulations conformed to a 2 (ST vs. NST) $\times 2$ (treatment with DEX vs. saline) $\times 2$ (test with DEX vs. saline) $\times 3$ (test sessions) experimental design. The first three conditions constituted between-group variables and the fourth was a within-subject dimension. A multivariate statistical model (i.e., multivariate analysis of variance [MANOVA] and Wilk's Lambda solution) was chosen for all analyses involving repeated measures (O'Brien \& Kaiser, 1985).

\section{Procedure}

Since the study was conducted in two identical replications, half of the groups within each replication were assigned either 4 or 5 subjects (balanced within ST conditions). Cell sizes were reversed for the subsequent replication so that all groups ultimately contained a total of 9 rats each.

Pretreatment training. Food intake was regulated over an 8day period until each subject achieved $80 \%$ of its preexperiment body weight (approximate). Thereafter, food availability was adjusted daily in an attempt to maintain these $80 \%$ values for the remainder of the study. Using these weights, a randomized-blocks procedure was followed (within each replication) to form eight groups of rats. Each subject then was given 9 consecutive days of barpress training. Session 1 involved 50 reinforced trials (single 0.045 -g Noyes food pellets dispensed after each barpress). Thereafter, sessions consisted of 100 continuous reward trials. The subjects were trained at about the same time each day, and group representation was balanced across the hourly time frames involved in the conduct of the study. The final four training sessions averaged approximately 20-25 min each.

Shock treatment. Five hours prior to placement in the ST chamber (Day 18), the subjects from half of the groups were given $400-\mu \mathrm{g} / \mathrm{kg}$ subcutaneous injections of DEX (approximately $0.1 \mathrm{cc}$ total volume) in the nape of the neck (see Kasper-Pandi, Hansing, \& Usher, 1970). Equivalent injections of physiologically normal saline were given to all others. Approximately $2 \mathrm{~min}$ (variable within $+1-60 \mathrm{sec}$ ) after they were put into the chamber, half of the subjects of each injection condition were each given a continuous, unsignaled, 180sec shock. The remaining subjects were treated identically, except that the switch controlling shock was off. This procedure was repeated on each of the next 4 consecutive days for a total of 5 treatment days (i.e., Days 18-22). The chamber was thoroughly cleaned, sawdust material beneath the grids was changed, and the entire apparatus was ventilated between treatments. The subjects immediately were returned to their home cages upon termination of each treatment session and, after Day 22, remained there to rest except for daily weighing and handling.

Testing. Restoration of pretreatment response levels began by giving each rat 50 additional barpress trials for food in the operant chamber on Day 31 (9 days following ST). Additional barpress train- 
ing was given to each on Days 37-40 (100 reinforced trials per day). Five hours prior to testing on Day 41 , half of the rats from each of the prior treatment conditions were injected with DEX (same dose and procedure), and the other rats were injected with saline.

Testing involved continued barpressing for food. However, the first response (if one occurred) following each 2 -min period produced a correlated 0.5 -sec shock through the grid floor. This continued until either five shocks were received or 10 min elapsed without a response. This procedure was repeated on Days 42 and 43 . The test chamber was thoroughly cleaned and fully ventilated between each test.

\section{RESULTS}

\section{Measures}

The computer registered the time required to complete the first 10 barpresses on Day 41 (prior to the first test shock), total barpresses and shocks received each session, and the elapsed time to the 1st and 10th responses following each test shock. Since all posttest-shock variables provided equivalent results, the number of shocks was chosen to represent these measures in order to preserve consistency with other reports (see Levine \& Levin, 1970) as well as to avoid redundancy. A $p$ value of $<.05$ (Wilk's Lambda criterion) was used throughout as the reference for statistical significance.

\section{Body Weight}

Body weight provided a partial manipulation check for the impact of DEX injections (see W. W. Beatty, Scouten, \& P. A. Beatty, 1971). Accordingly, weights reflecting the various facets of this study were chosen for analysis, including weights for the days prior to beginning the fooddeprivation regimen (Day 1$)$ and to ST (Day 17) $\left[F_{\mathrm{S}}(1,68)\right.$ $<1.0]$ and for the 5 treatment days (Days 18-22). A DEX-related weight loss was evident by the 2nd treatment day (Day 19) and increased in magnitude for each of the next 3 days of this period. These observations were confirmed by applying a 2 (ST and NST) $\times 2$ (treatment with DEX and saline) $\times 5$ (treatment sessions) MANOVA to the weights collected on Days 18-22. The $F$ values for days $[F(4,65)=56.28]$, injection $[F(1,68)=7.62]$, and the days $\times$ injection interaction $[F(4,65)=6.98]$ were significant. Follow-up pairwise comparisons involving injection condition resulted in significant and progressively larger $t$ values for each of Days 19-22. These analyses did not yield significant $F$ values for effects attributable to ST.

Despite the passage of 3 weeks without further injections, an analysis of the Day 40 , pretest body weights revealed lower body weights for the subjects given DEX during treatment $[F(1,68)=13.56$; no other $F$ s achieved significance]. Test-injection conditions also were associated with weight differences. As with treatment, presession DEX injections again resulted in progressively larger weight losses over days. The $F$ values resulting from the analysis of weights during testing (Days 41-43) reflected the perseverative effect of treatment DEX injections $[F(1,64)=11.83]$, the more immediate influence of test DEX injections $[F(1,64)=4.25]$, days $[F(2,63)$ $=113.02]$, and the interaction between test injection and days $[F(2,63)=37.97]$. Again, none of these analyses yielded significant $F$ values for effects involving ST.

\section{Behavioral Measures}

Baseline. Latency to make the initial 10 responses in the period prior to the first test shock of the first test session (Day 41) was used to assess the effect of the posttreatment response-stabilization procedure. Although these latencies were somewhat longer overall for ST than for NST groups (nonsignificant), the more important observation pertained to the effect of prior DEX injections. The subjects that had received DEX 3 weeks earlier (Days 18-22) took longer to emit the first 10 responses than did the saline-injected animals, regardless of prior ST exposure or current injection conditions.

These data were subjected to a 2 (ST and NST) $\times 2$ (treatment with DEX and saline) $\times 2$ (test with DEX and saline) ANOVA. (Analyses of covariance [ANCOVAs] also were performed in which Day 40 and Day 41 body weights respectively served as covariates. Moreover, the present baseline latencies subsequently were included as covariates in ANCOVAs that were applied to the remaining test data. In all cases, statistical outcomes were the same as those of the MANOVAs, and, accordingly, no further mention is made of these analyses.) The only significant $F$ value was that for treatment injection $[F(1,64)$ $=6.54]$.

Test data. Figure 1 displays the number of shocks, averaged over sessions, encountered by the respective ST (left panel) and NST (right panel) groups that were injected either with DEX (D) or saline (S) prior to treatment, testing, or both. Overall, NST groups received almost twice as many test shocks $(M=2.15)$ as did ST subjects $(M=1.24)$, regardless of injection condition(s). Moreover, the pattern of shocks received as a function of injection condition(s) was different for the NST groups than for the ST groups. Although somewhat fewer shocks were received by NST groups given DEX than by those given saline during treatment sessions (not significant), ST groups receiving identical injection conditions prior to both treatment and test sessions averaged significantly fewer $(33 \%)$ shocks $(M=1.0)$ than did those whose injection substances were switched $(M=1.5)$.

Several statistical analyses supported these observations. Among these was an overall 2 (ST and NST) $\times 2$ (treatment with DEX and saline) $\times 2$ (test with DEX and saline) $\times 3$ (test sessions) MANOVA that yielded significant $F$ values for the effects of ST $[F(1,64)=19.02]$, test sessions $[F(2,63)=220.3]$, and, among several interactions, for ST $\times$ treatment-injection $\times$ text sessions $[F(2,63)=8.6]$. These and the various interaction effects that resulted from appropriate follow-up analyses culminated in the application of 2 (treatment-injection conditions) $\times 2$ (test-injection conditions) ANOVAs to the data of each session and, separately, of each of the ST and NST group sets. 


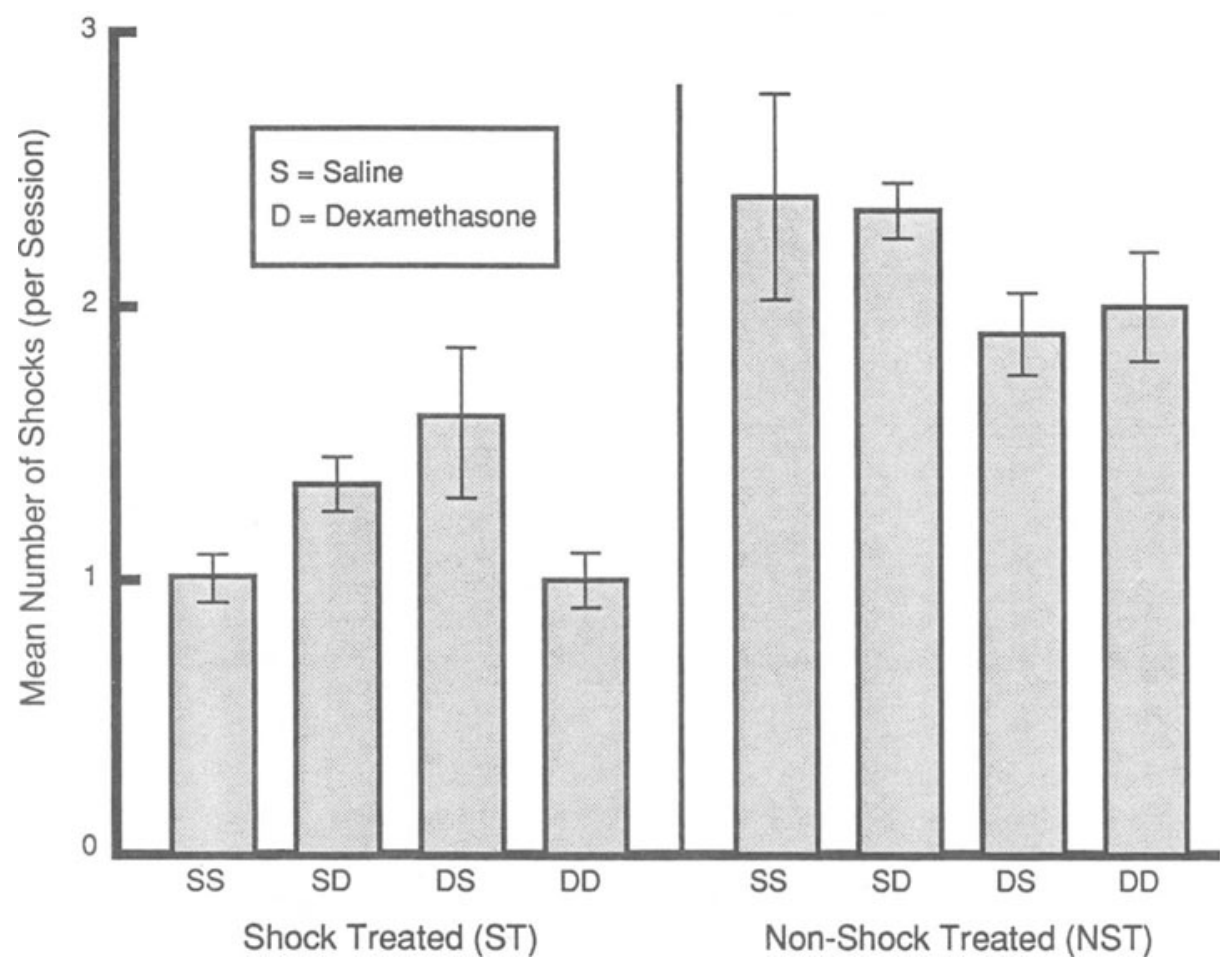

Figure 1. Mean number of shocks, averaged over subjects and sessions, for groups given shock treatment (ST; left panel) or no shock treatment (NST; right panel). Letters beneath each bar indicate injection conditions ( $(\mathrm{D}=$ dexamethasone; $\mathrm{S}=$ saline) for treatment and test phases.

Even though the $F$ ratio $[F(2,64)=3.75]$ for the treatment-injection $\times$ test sessions interaction involving the NST groups was significant, no $F$ values emerged significant for any of the three single-session analyses involving these subject sets. However, the $F$ values for the treatment-injection $\times$ test-injection interactions exceeded normally acceptable levels of statistical significance for each of the three single-session analyses involving the ST groups [all $F_{\mathrm{s}}(1,32)>4.5$ ]. Appropriate follow-up paired comparisons indicated that, in all but one case, these interactions were the result of fewer shocks encountered by ST groups that received identical rather than switched injection conditions for the treatment and test sessions. The single exception was for Session 2. Here, the ST group given saline during treatment and DEX during testing took somewhat fewer average shocks $(M=.33)$ than did groups injected with either saline $(M=.56)$ or DEX $(M=.70)$ for both phases. The other "switched" ST group (Group ST-DS) averaged 1.2 shocks for this session.

The present data permitted an evaluation of whether DEX injections given during testing and uncontaminated by prior DEX exposures retarded punishment learning, as reported by Levine and Levin (1970). Two such evaluations were possible, in the form of the pairs of NST and ST groups given DEX (or saline) prior to testing but not prior to the treatment sessions (Groups NST-SS versus NST-SD and Groups ST-SS versus ST-SD). During the first (but not subsequent) test session, both of the ST and NST groups injected with DEX received significantly more shocks than did their respective saline-injected counterparts. This partly was verified by an overall 2 (ST and NST) $\times 2$ (test-injection condition) $\times 3$ (test sessions) MANOVA that yielded significant $F$ s for ST, sessions, and the test-injection $\times$ sessions interaction $[F(2,31)=$ 4.27]. Follow-up separate-session analyses yielded significant $F$ s for the effects of ST for all three sessions $\left[F_{\mathrm{S}}(1,32)>6.39\right]$ and for the test-injection condition for Session $1[F(1,32)=5.6]$, but for no others.

\section{DISCUSSION}

The three most important findings of this study were a marked punishment-facilitation effect for ST, a transient attenuation in the standard punishment learning function traceable to the effect of DEX injections per se, and, more specific to the purpose of this study, evidence showing that the cue (but not pharmacological) effects of both ACTH and DEX apparently can partly mediate the punishmentaugmentation effect of ST.

The punishment-facilitation effect of ST most clearly was revealed in a comparison of the test performances of the ST and NST groups injected with saline for both the treatment and test phases of the study (Groups ST-SS vs. NST-SS). Overall, this NST group received almost 1.5 more shocks/session than did the ST-SS group. In- 
terference with punishment learning attributable exclusively to DEX was revealed by attenuated response suppression in the initial test session for test-injected-only (vs. non-DEX) groups, that is, Groups NST-SD versus NST-SS and possibly (see below for an alternative interpretation) Groups ST-SD versus ST-SS. This finding confirmed that of Levine and Levin (1970) in implicating ACTH as a determinant of punishment learning. It further suggested that ACTH may play only a partial role in regulating standard punishment functions, since its suppression (through injections of DEX) was not associated with attenuated punishment learning beyond the initial test session. Nonetheless, when considered together with the precipitous weight losses and diminished baseline performances for DEX-injected groups, this Day 1 punishmentattenuating effect also contributed as a manipulation check for the central pharmacological action of this drug (see also Beatty et al., 1971).

That ACTH cues may have served to at least partly mediate the punishment-facilitation effect of ST is revealed in a comparison of the overall test performances of Groups ST-SS and ST-SD. In considering the data of Madden et al. (1971), which showed elevated corticosterone (and hence ACTH; see Maier et al., 1986) levels in response to both treatment and test shocks, it is reasonable to assume that this condition similarly prevailed for Group ST-SS in the present study. Accordingly, the ACTH cues present during ST for this group may have become associatively linked with treatment concomitants and, when again elicited by test shocks, facilitated their memorial retrieval during punishment testing.

As noted, one concomitant of ST that is a likely candidate for associative linkage with ACTH cues is attenuated movement. The presence of ACTH cues in the test situation accordingly may have facilitated memorial retrieval of this immobility tendency. Because of compatibility with task demands, this would explain the augmented suppression of barpressing by Group ST-SS to the response-correlated test shocks. A similar logic also applies to the development of ACTH-linked training memories for Group ST-SD. However, injections of DEX during testing should have suppressed the reoccurrence of ACTH-linked cues in this group of subjects. The result may have been to offset the transfer of training memories to the test environment for these subjects, thereby attenuating the punishment-facilitation effect of ST.

Note that endogenous corticosterone and ACTH levels were correlated for the subjects of these two groups. This raises the possibility that corticosterone cue effects (along with or in lieu of ACTH effects) could have mediated the transfer of ST training memories to the test situation for Group ST-SS. There are several lines of evidence that argue against this interpretation. First, we were unable to locate consistent archival support for the possibility of conditionable cue effects for endogenous corticosterone. Second, of the numerous studies that explicitly included provisions for evaluating corticosterone involvement in the acquisition (Anderson et al., 1968; P. A. Beatty et al., 1970; Concannon et al., 1980; de Wied, 1974; Heins- broek et al., 1983; Kasper-Pandi et al., 1970), retention (Barrett, Leith, \& Ray, 1971; Berger, Starzec, \& Mason, 1981; Brush \& Levine, 1966; Herrmann, Hurwitz, \& Levine, 1984; Levine \& Brush, 1967), and extinction (Rigter et al., 1975) of aversively motivated responses, none showed significant contributions. Third, even if corticosterone cues were involved, this would not vitiate the major finding of this study that internal stimuli supplied by heightened PA activity serves a major role in mediating the punishment-facilitation effect of ST.

However, the equivalent test performances of Groups ST-SS and ST-DD seem to raise yet another problem for the ACTH-linked cue-effects interpretation presented here. If ACTH cues served as the exclusive source of the punishment-intensification effect of ST, then Group ST-DD, whose ACTH was suppressed (eliminated?) during both phases, should have performed more like Group NST-DD subjects. An explanation as to why this did not occur may be derived from findings showing that DEX also generates conditionable internal cues (Pappas \& Gray, 1971). These DEX cues conceivably could have substituted for the ACTH stimuli that normally become associated with ST. The reoccurrence of DEX cues during testing thus may have reinstated these associative concomitants in much the same way that was hypothesized for ACTH.

Support for this possibility is provided by the "switched" ST group that was given DEX only during treatment. In showing a marked attenuation of the punishmentfacilitation effect of ST, this group (i.e., Group ST-DS) performed like its NST control counterpart (i.e., Group NST-DS). Thus a possible explanation for this is that the ST training memory associated with DEX was not transferred to the test setting because saline was substituted therein for this synthetic hormone. That is, the absence of internal stimuli controlling ST training memory may have offset (due to generalization decrement) the transfer of postshock freezing to the test setting for this group.

Although consistent with FMR theory, the present analysis seems to require an extension of this notion in order to accommodate all of the results of this study. In showing that the cues supplied by DEX may link with training memories that, if present during testing, can facilitate their retrieval therein, a tentative deduction is that the internal stimuli that become associated with these memories can originate from various sources rather than exclusively from those supplied by ACTH. Indeed, the present findings, although perhaps redundant with the implications of the state-dependency theory of Overton $(1964,1973)$, support his assertion that the injection of any strong pharmacological agent may introduce problems because of the possibility of cue-effects substitution. In suppressing the endogenous effects of one agent, exogenous injections of another agent may substitute its own set of conditionable internal cues. If these latter cues enter into an associative linkage with the memorial by-products of a specified training/treatment regimen, they automatically become candidates for mediating transfer of such to a designated test.

The present study was not solely a test of FMR theory but instead was an attempt to evaluate its potential as an 
account of certain ST effects. In fact, most evaluations of FMR theory have involved neither the lengthy shock durations that we used nor a test environment that was physically dissimilar from the training setting. However, it is worth noting certain congruences between the procedures used in the present study and those used by Concannon et al. (1980) in their evaluation of FMR theory. They also administered multiple fixed-duration, unsignaled, and relatively intense shocks to subjects over consecutive days in a setting that was physically dissimilar from their test environment. They further assumed that ACTH liberation from these shocks would become associated with the concomitants of this treatment, that is, fear. They reasoned that when subjects subsequently were injected with ACTH in a distinctive environment, the cues of this hormone would serve as a source of acquired fear. As a result of second-order conditioning, there should be associative linkage with the static contextual stimuli in the environment. This logic was supported by their showing that these subjects (but not appropriate control rats) avoided this distinctive setting.

Although training-shock parameters and test procedures varied greatly between the study of Concannon et al. (1980) and the present, the general similarities in approach and outcome nonetheless may be taken as external validation of a portion of the present findings. That ACTH did not seem to be exclusively responsible for the present ST effects may be related to the unusually long durations of the treatment shocks that were used. These long shocks may have been a source of conditionable cues over and above those supplied by ACTH (or DEX). The test shocks per se thus could have reinstated memories that originally became linked to these treatment-shock cues.

It is of interest to speculate on the relationship between the present findings and those of others who have investigated the various biopharmacological consequences of ST as possible mediators of its effects. There are numerous reports involving various aspects of ST that have evaluated the possible contributions of endogenous opioids (Maier, Laudenslager, \& Ryan, 1985), central neurochemical transmitter agents related to motor function (Anisman, Kokkinidis, \& Sklar, 1981; Weiss, Glazer, \& Pohorecky, 1976), and possible PA involvements (Dess, Linwick, Patterson, Overmier, \& Levine, 1983; Levine, Madden, Conner, Moskal, \& Anderson, 1973; Maier et al., 1986). Although several investigators have located circumstances wherein certain of these processes may be involved, none have shown these biophysiological concomitants to be pivotal determinants of most of the important effects revealed for ST. The present report is not an exception in this regard. There was no evidence supporting involvement of the PA system in mediating ST effects beyond that supplied by the cue effects of certain of its secretions.

\section{REFERENCES}

AHLERS, S. T., \& RicharDson, R. (1985). Administration of dexamethasone prior to training blocks ACTH-induced recovery of an extinguished avoidance response. Behavioral Neuroscience, 99, 760-764.
Anderson, D. C., Cole, J., \& MCVaugh, W. (1968). Variations in signalled inescapable preshock as determinants of responses to punishment. Journal of Comparative \& Physiological Psychology: Monograph Supplement, 65(3, Pt. 2), 1-17.

anderson, D. C., Crowell, C. R., Cunningham, C. L., \&upo, J. V. (1979). Behavior during shock exposure as a determinant of subsequent interference with shuttlebox escape-avoidance learning in the rat. Journal of Experimental Psychology: Animal Behavior Processes, 5, 243-257.

ANDERSON, D. C., WinN, W., \& TAM, T. (1968). Adrenocorticotrophic hormone and acquisition of a passive avoidance response: A replication and extension. Journal of Comparative \& Physiological Psychology, 66, 197-199.

Anisman, H., Kokkinidis, L., Sklar, L. S. (1981). Contribution of neurochemical change to stress-induced behavioral deficits. In S. J. Cooper (Ed.), Theory in psychopharmacology (pp. 65-102). London: Academic Press.

BALLeINe, B., \& JoB, R. F. S. (1991). Reconsideration of the role of competing responses in demonstrations of the interference effect (learned helplessness). Journal of Experimental Psychology: Animal Behavior Processes, 17, 270-280.

Barrett, R. J., Leith, N. J., \& RAY, O. S. (1971). The effects of pituitary-adrenal manipulations on time-dependent processes in avoidance learning. Physiology \& Behavior, 7, 661-665.

Beatty, P. A., Beatty, W. W., Bowman, R. E. , \& Gilchrist, J. C. (1970). The effects of $\mathrm{ACTH}$, adrenalectomy and dexamethasone on the acquisition of an avoidance response in rats. Physiology \& Behavior, 5, 939-944.

Beatty, W. W., Scouten, C. W., \& Beatty, P. A. (1971). Differential effects of dexamethasone and body weight loss on two measures of activity. Physiology \& Behavior, 7, 869-871.

Berger, D. F., Starzec, J. J., \& Mason, E. B. (1981). The relationship between plasma corticosterone levels and leverpress avoidance vs. escape behaviors in rats. Physiological Psychology, 9, 81-86.

Britton, K. T., LeC, G., Bana, R., Risch, S. C., \& KoOB, G. F. (1986). Activating and 'anxiogenic' effects of corticotropin releasing factor are not inhibited by blockade of the pituitary-adrenal system with Dexamethasone. Life Sciences, 39, 1281-1286.

BRUSh, F. R., \& LeVINE, S. (1966). Adrenocortical activity and avoidance learning as a function of time after fear conditioning. Physiology \& Behavior, 1, 309-311.

Campeell, B. A., \& Teghtsoonian, R. (1958). Electrical and behavioral effects of different types of shock stimuli on the rat. Journal of Comparative \& Physiological Psychology, 51, 185-192.

Concannon, J. T., Riccio, D. C., Maloney, R., MCKelvey, J. (1980). ACTH mediation of learned fear: Blockade by naloxone and naltrexone. Physiology \& Behavior, 25, 977-979.

Crowell, C. R., \& ANDERSon, D. C. (1981). Influence of duration and number of inescapable shocks on intrashock activity and subsequent interference effects. Animal Learning \& Behavior, 9, 28-37.

Dess, N. K., Linwick, D., Patterson, J., Overmier, J. B., \& LeVINE, S. (1983). Immediate and proactive effects of controllability and predictability on plasma cortisol responses to shocks in dogs. Behavioral Neuroscience, 97, 1005-1016.

DE WIED, D. (1974). Pituitary-adrenal system hormones and behavior. In F. O. Schmitt \& F. G. Worden (Eds.), The neurosciences: Third study program (pp. 653-666). Cambridge: MIT Press.

Heinsbroek, R. P. W., Van Oyen, H. G., Van De Poll, N. E., \& BoER, G. J. (1983). Failure of dexamethasone to influence sex differences in acquisition of discriminated lever press avoidance. Pharmacology, Biochemistry \& Behavior, 19, 599-604.

Hennessy, J. W., Smotherman, W. P., \& Levine, S. (1980). Investigations into the nature of dexamethasone and ACTH effects upon learned taste aversion. Physiology \& Behavior, 24, 645-649.

Herrmann, T. F., Hurwitz, H. M. B., \& Levine, S. (1984). Behavioral control, aversive stimulus frequency, and pituitary-adrenal response. Behavioral Neuroscience, 98, 1094-1099.

Kasper-Pandi, P., Hansing. R., \& Usher, D. R. (1970). The effect of dexamethasone blockade of ACTH release on avoidance learning. Physiology \& Behavior, 5, 361-363.

Lamberts, S. W. J., Bons, E., \& ZuiderWiJK, J. (1986). High concentrations of catecholamines selectively diminish the sensitivity of 
crf-stimulated ACTH release by cultured rat pituitary cells to the suppressive effects of dexamethasone. Life Sciences, 39, 97-102.

Levine, S., \& Brush, F. R. (1967). Adrenocortical activity and avoidance learning as a function of time after avoidance training. Physiology \& Behavior, 2, 385-388.

LEVINE, S., JONES, L. (1965). Adrenocorticotrophic hormone (ACTH) and passive avoidance learning. Journal of Comparative \& Physiological Psychology, 59, 357-360.

Levine, S., Levin, R. (1970). Pituitary-adrenal influences on passive avoidance in two inbred strains of mice. Hormones \& Behavior, 1, 105-110

Levine, S., Madden, J., Conner, R. L., Moskal, J. R., \& Anderson, D. C. (1973). Physiological and behavioral effects of prior aversive stimulation (preshock) in the rat. Physiology \& Behavior, 10. 467-471.

Mactutus, C. F., Smith, R. L., Riccio, D. C. (1980). Extending the duration of ACTH-induced memory reactivation in an amnestic paradigm. Physiology \& Behavior, 24, 541-546.

Madden, J., IV, Rollins, J., Anderson, D. C., Conner, R. L., \& LeVINE, S. (1971). Preshock-produced intensification of passive avoidance responding and of elevation in corticosteroid level. Physiology \& Behavior, 7, 733-736.

Maier, S. F., Laudenslager, M. L., \& Ryan, S. M. (1985). Stressor controllability, immune function, and endogenous opiates. In F. R. Brush \& J. B. Overmier (Eds.), Affect, conditioning, and cognition: Essays on the determinants of behavior (pp. 183-202). Hillsdale, NJ: Erlbaum.

Maier, S. F., Ryan, S., Barksdale, C. M., \& Kalin, N. H. (1986). Stressor controllability and the pituitary-adrenal system. Behavioral Neuroscience, 100, 669-674.

MCGAugh, J. L. (1983). Hormonal influences on memory. Annual Review of Psychology, 34, 297-323.

McGaugh, J. L., Gold, P. E., Van Buskirk, R., \& Haycock, J. (1975). Modulating influences of hormones and catecholamines on memory storage processes. In W. H. Gispen, T. B. van Wimersma Greidanus, R. Bohus, \& D. de Wied (Eds.), Progress in brain research: Hormones, homeostasis, and the brain (Vol. 42, pp. 151-162). Amsterdam: Elsevier.

MinekA, S., Cook, M., Miller, S. (1984). Fear conditioned with escapable and inescapable shock: Effects of a feedback stimulus. Journal of Experimental Psychology: Animal Behavior Processes, 10. 307-323.
O'Brien, R. G., \& Kaiser, M. K. (1985). MANOVA method for analyzing repeated measures design: An extensive primer. Psychological Bulletin, 97, 316-333.

Overton, D. A. (1964). State dependent learning and drug discriminations. In L. L. Iversen, S. D. Iversen, \& S. H. Snyder (Eds.), Handbook of psychopharmacology: Drugs, neurotransmitters, and behavior (Vol. 18, pp. 59-128). New York: Plenum.

OVERTON, D. A. (1973). State-dependent learning produced by addicting drugs. In S. Fisher \& A. Freedman (Eds.), Opiate addiction: origins and treatment. Washington, DC: Winston.

PAppas, G. A., GrAy, P. (1971). Cue value of dexamethasone for fear-motivated behavior. Physiology \& Behavior, 6, 127-130.

Riccio, D. C., Concannon, J. T. (1981). ACTH and the reminder phenomena. Іл J. L. Martinez, Jr., R. A. Jensen, R. B. Messing. H. Rigter, \& J. L. McGaugh (Eds.), Endogenous peptides and leaming and memory processes (pp. 117-142). New York: Academic Press.

Richardson, R., Riccio, D. C., \& Devine, L. (1984). ACTH-induced recovery of extinguished avoidance responding. Physiological Psychology, 12, 184-192.

Rigter, H., Elbertse, R., \&An Riezen, H. (1975). Time-dependent anti-amnestic effect of $\mathrm{ACTH}_{4-10}$ and desglycinamidelysine vasopressin. In W. H. Gispen, T. B. van Wimersma Greidanus, R. Bohus, \& D. de Wied (Eds.), Progress in brain research: Hormones, homeostasis, and the brain (Vol. 42, pp.163-171). Amsterdam: Elsevier.

SEgGiE, J., Brown, G. M. (1973). Effect of dexamethasone on affective behavior and adrenal reactivity following septal lesions in the rat. Journal of Comparative \& Physiological Psychology, 83, 60-65.

WALTERS, G. C., \& Rogers, J. V. (1963). Aversive stimulation of the rat: Long-term effects on subsequent behavior. Science, 142, 70-71.

Weiss, J. M., Glazer, H. I., \& Pohorecky, L. A. (1976). Coping behavior and neurochemical changes: An alternative explanation for the original "learned helplessness" experiments. In G. Serban \& A. Kling (Eds.), Animal models in human psychobiology (pp. 141 173). New York: Plenum.

(Manuscript received July 2, 1992; revision accepted for publication October 19, 1992.) 